REFERENCES

Balch, C. C. (1950). Brit. F. Nutr. 4, 36I.

Balch, C. C., Bartlett, S. \& Johnson, V. W. (195I). F. agric. Sci. 4I, 98.

Balch, C. C. \& Johnson, V. W. (1950). Brit. F. Nutr. 4, 389.

Kellner, O. (1907). Die Ernährung der Landwirtschaftlichen Nutztiere, $4^{\text {th }}$ ed. Berlin: Paul Taray.

Larsen, C., Hungerford, E. H. \& Bailey, D. E. (I917). Bull. S. Dak. agric. Exp. Sta. no. 175.

Wood, T. B. (1927). Bull. Minist. Agric., Lond., no. 48, 5th ed.

Woodman, H. E. (1948). Bull. Minist. Agric., Lond., no. 48, i ith ed.

Woodward, T. E. \& McNulty, J. B. (193I). Tech. Bull. U.S. Dep. Agric. no. 278.

\title{
Evidence of an Inherited Factor in Trophopathic Hepatitis
}

\author{
By A. J. LEA \\ I34 Bispham Road, Bispham, Lancs
}

(Received 8 October 1952)

It is well known that dietary insufficiency in experimental animals can produce necrosis of the liver parenchyma, with subsequent development of fibrous tissue (Himsworth, 1947). It was, therefore, not surprising to find evidence of permanent liver damage in service personnel who had been prisoners of war in Japanese hands. No evidence, however, could be found of any correlation between the presence of liver damage and of other more obvious signs of malnutrition. Such damage did not bear any apparent relationship to the overall degree of malnutrition. It might have been expected that liver damage would have been widespread in the various prison camps, but in fact this was not so. The condition occurred apparently at random, and whereas a few men in each camp developed it, the majority - presumably on the same diet-did not do so. In an attempt to find an explanation of this curious distribution, all possible facts relating to these cases were recorded, and it was found that the only factor that appeared to have any relationship to the incidence of liver damage was the degree of pigmentation of the eyes and hair of the individual. This implies an inherited liver abnormality linked in some way with pigmentation.

\section{METHODS}

Collection of data. Information was being collected as part of a general programme for the investigation of the possibility of an association between susceptibility to disease and eye and hair colour. An attempt has been made to include all available cases of the diseases under discussion in which the eye and hair colours of the patient were recorded. The data are taken from the records of service personnel in the possession of the Ministry of Pensions. They are not entirely unselected as they refer to the male sex only and are necessarily limited to the service age groups; the men concerned were considered to be of a standard of physical fitness suitable for service in the Armed Forces. All the men were born in the United Kingdom, and their age 
groups and the geographical distribution of their birth places show no significant differences from those of the control series.

Classification. It must be emphasized that the data inevitably contain many uncertainties and that the magnitude of these cannot be estimated. The records of eye and hair colours were made by members of recruiting boards who cannot be supposed to have been unduly interested in the exact description of such characters. The records were made by many different persons, doubtless with differing ideas on the meaning of such terms as 'fair', 'light brown', 'hazel'. In fact, it may be stated that there is no standard classification of these characters in general use, and their description is left to the taste of the individual examiner. On the other hand, it must be remembered that the control series are also subject to the same uncertainties of classification, which undoubtedly reduces the effects of the errors. For the purposes of this paper, blue, grey and blue-grey eyes have been classed together as 'blue', hazel and brown eyes as 'dark', fair, blond and light brown hair as 'blond', medium brown, brown, dark brown and black hair as 'dark'. MacConaill's classification into four types (MacConaill, $\mathrm{r}$ 94I-2) has been used, this being blue eyes and blond hair=blond, dark eyes and dark hair $=$ dark, blue eyes and dark hair=glaucope, dark eyes and blond hair $=$ cyanope.

Diagnosis. Further difficulties were encountered in the diagnosis of cirrhosis, Banti's syndrome and even of infective hepatitis. A survey of current literature on liver diseases shows that many different terms are in use by different schools. It is now generally recognized (Himsworth, 1947; Dible, 195I) that it is impossible to ascertain the aetiology of a cirrhosis by histological examination. These difficulties were so great, particularly in the Banti syndrome, that certain definitions have been adopted for the present purposes. Cirrhosis here means a cirrhotic condition of the liver in an individual without any history of infection, malnutrition or other external factors except alcoholism. The Banti syndrome is defined as fibrosis of the liver and spleen with an associated hypochromic anaemia, with no evidence of infection or other external factors, including alcoholism. The term infective hepatitis has been extended to include conditions such as homologous serum jaundice, arsenical poisoning and T.N.T. poisoning, and has therefore been replaced by the expression toxipathic hepatitis introduced by Himsworth \& Glynn (1944).

\section{RESULTS}

The results are presented in Table $\mathrm{I}$.

Liver damage in ex-prisoners of war. The evidence of liver damage in these cases ranges from clinical hepatomegaly to complete investigations of liver function and biopsy. All such cases have been included as 'liver damage', and no attempt has been made to estimate the degree. As infections such as infective hepatitis and amoebic and bacillary dysentery were widespread in the prison camps, there can be little doubt that malnutrition was not the only factor involved. On the other hand, it is very probable that many cases of so-called 'clinical dysentery' were in fact nutritional diarrhoea, and it is impossible to exclude the effects of malnutrition.

There have been recorded 1496 cases of ex-prisoners of war with evidence of 
malnutrition, in all degrees, and in 182 of them there was evidence of liver damage present at least 5 years after repatriation. It will be seen (Table $\mathrm{I}$ ) that whereas in prisoners of war as a whole there were $34.8 \%$ of the dark type, in those with liver damage the percentage was $48 \cdot 9$. Comparison of these figures gave $\chi^{2}=18 \cdot 669$, from which, with 3 degrees of freedom, $P$ was less than o.001. The contribution to $\chi^{2}$ by the excess of dark types and deficiency of blond was $15.34^{\circ}$, the glaucopes and cyanopes being almost unaffected.

Cirrhosis. It was thought that further information might be obtained by an investigation of cases of cirrhosis, as defined above. It is necessary to point out that 'cirrhosis' is here diagnosed on what is known of the previous history of the case, and that it is quite possible that some of these cases did originate in an infection, as such histories can seldom be complete. There is the additional disturbing feature that cases of infective hepatitis without jaundice occur, and may be incorrectly diagnosed.

Table $\mathrm{I}$. Number of cases and percentage distribution of liver disease in members of the Armed Forces, classified according to eye and hair colour and compared with controls

\begin{tabular}{|c|c|c|c|c|c|c|c|c|c|}
\hline & $\begin{array}{c}\text { A } \\
\text { Prisoners } \\
\text { of war } \\
\text { with } \\
\text { liver } \\
\text { damage }\end{array}$ & $\begin{array}{c}\text { B } \\
\text { Prisoners } \\
\text { of war } \\
\text { without } \\
\text { liver } \\
\text { damage }\end{array}$ & $\begin{array}{c}\text { C } \\
\text { Service } \\
\text { personnel } \\
\text { with } \\
\text { cirrhosis }\end{array}$ & $\begin{array}{c}\text { D } \\
\text { Service } \\
\text { personnel } \\
\text { with } \\
\text { Banti's } \\
\text { syndrome }\end{array}$ & $\begin{array}{c}\mathrm{E} \\
\text { Service } \\
\text { personnel } \\
\text { with } \\
\text { toxipathic } \\
\text { hepatitis }\end{array}$ & $\begin{array}{c}F \\
\text { Service } \\
\text { personnel } \\
\text { with } \\
\text { injury }\end{array}$ & $\begin{array}{c}\text { Tropho- } \\
\text { pathic } \\
\text { hepatitis }\end{array}$ & $(B+F)$ & $\begin{array}{l}\text { Total } \\
\text { cases }\end{array}$ \\
\hline Blond & $\begin{array}{c}23 \\
(12 \cdot 6)\end{array}$ & $\begin{array}{l}248 \\
(18 \cdot 8)\end{array}$ & $\begin{array}{l}4 \\
(4 \cdot 0)\end{array}$ & $\begin{array}{c}I 6 \\
(I I \cdot I)\end{array}$ & $\begin{array}{l}5^{8} \\
(17 \cdot 1)\end{array}$ & $\begin{array}{l}977 \\
\left(\mathrm{r} 9^{\circ} \mathrm{I}\right)\end{array}$ & $\begin{array}{l}27 \\
(9 \cdot 6)\end{array}$ & $\begin{array}{l}1225 \\
\left(19^{\circ} 0\right)\end{array}$ & 1326 \\
\hline Dark & $\begin{array}{c}89 \\
(48 \cdot 9)\end{array}$ & $\begin{array}{c}43 \mathrm{I} \\
(32 \cdot 8)\end{array}$ & $\begin{array}{c}50 \\
(50 \cdot 0)\end{array}$ & $\begin{array}{c}59^{\circ} \\
\left(41^{\circ} 0\right)\end{array}$ & $\begin{array}{l}142 \\
(42 \cdot 0)\end{array}$ & $\begin{array}{r}1835 \\
(35 \cdot 8)\end{array}$ & $\begin{array}{l}\text { I39 } \\
\left(49^{\circ} 3\right)\end{array}$ & $\begin{array}{r}2266 \\
\left(35^{\prime} \cdot 2\right)\end{array}$ & 2606 \\
\hline Glaucope & $\begin{array}{c}64 \\
(35,2)\end{array}$ & $\begin{array}{l}574 \\
\left(43^{\circ} 7\right)\end{array}$ & $\begin{array}{c}44 \\
(44 \cdot 0)\end{array}$ & $\begin{array}{c}62 \\
(43 \cdot I)\end{array}$ & $\begin{array}{l}124 \\
(36 \cdot 7)\end{array}$ & $\begin{array}{c}2063 \\
(40 \cdot 2)\end{array}$ & $\begin{array}{l}108 \\
(38 \cdot 3)\end{array}$ & $\begin{array}{r}2637 \\
\left(40^{\circ} 9\right)\end{array}$ & 2931 \\
\hline Cyanope & $\begin{array}{c}6 \\
(3 \cdot 3)\end{array}$ & $\begin{array}{l}6 \mathrm{I} \\
(4 \cdot 6)\end{array}$ & $\stackrel{2}{(2 \cdot 0)}$ & $\begin{array}{l}7 \\
(4 \cdot 8)\end{array}$ & $\begin{array}{l}\text { I4 } \\
(4 \cdot 2)\end{array}$ & $\begin{array}{l}252 \\
(4 \cdot 9)\end{array}$ & $\begin{array}{c}8 \\
(2 \cdot 8)\end{array}$ & $\begin{array}{l}313 \\
\left(4^{\circ} 9\right)\end{array}$ & 342 \\
\hline Total & 182 & 1314 & 100 & I 44 & $33^{8}$ & 5127 & 282 & 6441 & 7205 \\
\hline
\end{tabular}

One hundred cases of cirrhosis have been collected, with a proportion of blonds $4.0 \%$ and of darks $50.0 \%$. It will be seen that the ratio of blonds to darks is even more disturbed in these cases than in the prisoners of war with liver damage. A series of $5^{127}$ cases of injury in service personnel, and therefore drawn from the same age groups as the disease series, had previously been prepared as a control for investigations into the association of pigmentation with disease (Lea, 1952), with percentages of blonds I $9^{\cdot I}$ and of darks $35 \cdot 8$. The cirrhosis cases were compared with this series, $\chi^{2}$ being 19.353, from which, with 3 degrees of freedom, $P$ was less than 0.001 . The excess of dark types and deficiency of blonds contributed 17.362 to the value of $\chi^{2}$.

Comparison of the cases of cirrhosis with those of liver damage in prisoners of war series (together constituting the trophopathic group of Himsworth \& Glynn, 1944) gives $\chi^{2}=6 \cdot 75^{\circ}, P$ being between 0.05 and 0.1 . Comparison of the prisoners of war without liver damage with the series of injuries gives $\chi^{2}=5.860, P$ being between 0.3 and 0.5 . Neither of these values is significant and it is therefore legitimate to compare the trophopathic group with the combined control series. This gives $\chi^{2}=3^{\circ} \cdot 744$, 
$P$ being much less than 0.001 . The excess of darks and deficiency of blonds contribute $27^{\cdot 942}$ to the value of $\chi^{2}$. If the data were free from uncertainties these findings would leave no reasonable doubt on the question of an association of trophopathic hepatitis with the dark type.

Toxipathic hepatitis. The possibility of such an association in toxipathic hepatitis was now considered. Three hundred and thirty-eight cases of this type were collected with blonds $17 \cdot 1 \%$ and darks $42 \cdot 0 \%$. There was again an excess of dark types, but the blond: dark ratio was not so much disturbed as in the trophopathic series. Comparison with the combined control series gave $\chi^{2}=6.554, P$ between 0.05 and 0.1 , a non-significant finding.

Banti's syndrome. The question of Banti's syndrome was then investigated. One hundred and forty-four cases were collected, blonds being I I $\mathrm{I} \%$ and darks $4 \mathrm{r} \cdot 0 \%$. Comparison of these with the combined control series gave $\chi^{2}=6 \cdot 233, P$ between $0 \cdot 1$ and 0.2 . Comparison with the trophopathic cases gave $\chi^{2}=3.248, P$ between 0.3 and 0.5 . Comparison with the toxipathic series gave $\chi^{2}=3.586, P$ between 0.3 and 0.5 . None of these findings is significant, but it will be seen that there was considerable disturbance of the blond: dark ratio with excess of darks.

Thyrotoxicosis and primary hepatoma. A search was made for cases of thyrotoxicosis in which there was evidence of liver damage (trophopathic hepatitis). Only seven were found, none being blond and two dark. In view of the fact that most, if not all, hepatomas originate in fibrotic livers, cases of this also were collected. Fourteen were obtained, including three blonds and six darks. (A hepatoma may originate in either toxipathic or trophopathic hepatitis.) The numbers of cases of these diseases were too small for any use to be made of them.

\section{DISCUSSION}

These findings, even when errors of classification and diagnosis are taken into consideration, provide strong evidence of the presence of a hereditary factor predisposing to necrosis of the liver parenchyma and associated with the dark type of man. They also suggest that the effects of toxipathic hepatitis are independent of this hereditary factor. However, it is well known that the end-results of toxipathic hepatitis cannot be distinguished from those of trophopathic origin, so that we may have here yet one more example of a condition due to environmental factors that, in its end-results, is indistinguishable from one with a hereditary basis (Snyder, 195I). This statement is in no way intended to mean that trophopathic hepatitis is purely a hereditary condition. Obviously an external factor is necessary for its production. This factor may be the lack of some essential nutrient, the nature of which is still undetermined, or failure to absorb this substance, or excessive use of or loss of it from the body. It is the tendency to necrosis that is inherited, not the end-result. Nor does this mean that members of the other pigmentary groups cannot develop trophopathic hepatitis. It merely means that the dark type responds to a much smaller external stimulus or to a stimulus acting over only a comparatively short period of time.

The nature of this inherited factor can only be a matter for speculation at present. 
It is well known that oxygen deficiency in the circulating blood is a factor in necrosis of the liver parenchyma (Buchner, 1942). It is also well established that the left lobe of the liver suffers far more severely than the right in trophopathic hepatitis and this has been explained by the 'stream-line' findings in the portal circulation (Séregé, I902; Copher \& Dick, 1928). Himsworth (1947) has summarized the mechanism of production of dietetic necrosis as follows: 'Dietetic necrosis is a disease due to a nutritional deficiency; digestion occurs in the small intestine; its products are carried in the blood of the superior mesenteric vein which supplies the right lobes of the liver. When the diet is adequate, the amount of the essential nutrient in the portal blood is high and sufficient escapes through the liver to reach the arterial blood and so nourish the left lobes. When, however, the diet is partly deficient most of the nutrient is removed by the right lobes, inadequate amounts get through to the left, and ultimately massive necrosis develops there.'

An inherited abnormality of the liver might then take one of two forms, (a) anatomical or (b) physiological. (a) An anatomical abnormality in the distribution of the hepatic artery to the left lobe of the liver is a possibility for either nutritional or oxygen deficiency. As, however, no such abnormality has ever been demonstrated in experimental animals (Himsworth, 1947), this appears to be very improbable. (b) A physiological abnormality associated with a particular physical type has much evidence in its favour. Marked variation in the susceptibility of different strains of rats to inadequate diets has been noted. Rats from the Glaxo colony of Wistar origin were found, in the majority of cases, to develop severe liver damage in $30-5^{\circ}$ days when on the most effective of these diets. Rats from an impure albino strain required about roo days, whereas black-hooded rats either survived unharmed or showed only mild and partial lesions after 200 days on the same diet (Himsworth, 1947). Differences in methionine metabolism in the liver in different strains of rats have been demonstrated by Rutman, Dempster \& Tarver (1949), Roth \& Allison (1950) and Brown \& Allison (1948), and in chickens by Waters, Groschke \& Scott (I950). Widdowson (1947) has described the striking differences in food consumption by both children and adults having the same physical characteristics. It was found that in each age group studied there was always one individual who ate twice as much as another, and that similar differences occurred when such characters as weight, height and surface area were equal. Widdowson also points out that these extreme variations from the mean were compatible with normal physical development, and that her findings indicate that individual requirements must differ as much as individual intakes. It should be noted that eye and hair colour were not among the physical characteristics investigated by Widdowson. It is therefore quite within the bounds of probability that those individuals who develop trophopathic hepatitis may have some unusual inherited form of metabolism of an essential nutrient.

The nature of the association with the dark type must also, on the available evidence, remain a subject for conjecture. It will be noted that in every instance the excess of dark types is at the expense of the blonds, the glaucopes and cyanopes showing little change. It is possible that this association might be direct, the dark type and the liver abnormality being manifestations of the same gene. The presence of a number of 
blonds in the abnormal group could then be explained by the uncertainties of aetiology and diagnosis, as infection may, and undoubtedly does in the prisoner-of-war series, account for some of the cases recorded as trophopathic hepatitis. Phenylalanine and tyrosine metabolism would then be suspect, because of their known association with pigmentation. On the other hand, it is known that dark eye and dark hair in man are functions of separate genes, though linked, so that an explanation based on direct association is highly improbable. Far more probable is an indirect association, that is, a condition due to a gene carried on the same chromosome as are the genes for dark hair and dark eye colours and therefore exhibiting linkage. The data contain too many uncertainties to allow of any attempt to discuss such a linkage in detail.

The question of Banti's syndrome needs further consideration. It has been shown that the eye and hair colours in the cases of this disease do not differ significantly from the control, the toxipathic or the trophopathic series. There is, however, again a considerable disturbance of the blond:dark ratio in the direction of excess of the dark type. This syndrome was found to be the most difficult to deal with of the diseases considered in this paper. The literature reveals much divergence of opinion on its precise definition. McMichael (1934) showed that many cases so diagnosed were in fact somewhat unusual examples of other well-known conditions and was of the opinion that the remainder were probably variants of hepatic cirrhosis. On the other hand, Tidy (1952) regards the syndrome as a manifestation of erythroblastosis foetalis. The more general view appears to be that, whereas many cases so diagnosed are really variants of massive hepatic necrosis, there are others for which this explanation does not account. The evidence in the present series does not allow any conclusion to be drawn.

In the cases of toxipathic hepatitis there is again this disturbance of the blond: dark ratio, though not so marked as in the Banti syndrome series. Diagnosis again presents a difficulty, as cases with the clinical picture of infective hepatitis or homologous serum jaundice, arising in circumstances in which these diseases may be expected to occur, may nevertheless in reality be cases of ordinary cirrhosis with an exacerbation of symptoms. A history of chronic alcoholism is not uncommon in syphilitics, in which liver involvement is attributed to homologous serum jaundice or to arsenical poisoning due to anti-syphilitic treatment in progress.

It must be emphasized that the presence of an inherited liver abnormality cannot be regarded as established. This never can be done on the type of data, however extensive these may eventually become, on which this paper is based. The sources of error are too numerous. The most that can be said is that the presence of such a factor is strongly indicated, and the hypothesis is put forward as a suggestion for further more accurate investigation. However, Himsworth (1947) has pointed out that post-necrotic scarring after massive hepatic necrosis in cases in which there is no history of poisoning or infection raises the possibility that nutrition may be a significant factor. He has also pointed out that when such lesions occur in men living under the conditions of western civilization, dietary deficiency per se is an insufficient explanation. It is suggested that an inherited metabolic abnormality of the liver provides the necessary explanation. 
It is difficult to see how a final answer can be given until an accurate classification of eye and hair colours has been evolved and the diagnosis of liver diseases placed on a firm basis. A detailed description of eye colours has been produced by Riddell (I942), but hair-colour classification is still in an unsatisfactory state. The following quotation from Himsworth (1947) shows that greater accuracy in the diagnosis of liver diseases is to be expected to follow improvement in clinical rather than histological techniques: 'But whether the pathological lesion is produced by chemical, infective or nutritional agents it has the same anatomical form in all, and in consequence the clinical features referable to hepatic damage in the various illnesses are indistinguishable and in no way characteristic of the causative factor. The detection of the cause in an individual case thus depends upon recognition of the general features of extra-hepatic effects peculiar to that particular causative agent.'

\section{SUMMARY}

I. Evidence is presented of an inherited abnormality of the liver in cases of trophopathic hepatitis, associated with dark eye and hair colour. This abnormality appears to be physiological rather than anatomical.

2. It is suggested that such an abnormality would account for $(a)$ the irregular incidence of liver damage in cases of frank malnutrition and $(b)$ cases of cirrhosis, in which there is no evidence of external factors, occurring among the inhabitants of western civilization.

3. No such evidence has been found in cases of toxipathic hepatitis.

4. These findings are not conclusive and are only to be regarded as a basis for further investigation.

I wish to acknowledge my indebtedness to the Director-General of Medical Services of the Ministry of Pensions for permission to publish the evidence taken from the records of service cases, and to Messrs Blackwell, Scientific Publications, Ltd., for permission to publish the quotations from Professor Himsworth's book.

The work has been carried out with the aid of a grant from the Government Grant Committee of The Royal Society.

\section{REFERENCES}

Brown, J. H. \& Allison, J. B. (1948). Proc. Soc. exp, Biol., N.Y., 69, 196.

Buchner, H. (1942). Quoted in Bull. War Med. (1943), 3, 499.

Copher, G. H. \& Dick, B. M. (1928). Arch. Surg., Chicago, 17, 408.

Dible, J. H. (I95I). Brit. med. F. i, 833 .

Himsworth, H. P. (1947). Lectures on the Liver and its Diseases. Oxford: Blackwell.

Himsworth, H. P. \& Glynn, L. E. (1944). Lancet, 246, 457.

Lea, A. J. (1952). Thorax, 7, 305.

MacConaill, M. A. (194I-2). Ann. Eugen., Lond., II, I73.

McMichael, J. (1934). F. Path. Bact. 39, 481.

Riddell, W. J. B. (1942). Ann. Eugen., Lond., r1, 245.

Roth, J. S. \& Allison, J. B. (1950). F. biol. Chem. 183, I73.

Rutman, R., Dempster, E. \& Tarver, H. (1949). F. biol. Chem. I77, 49 I.

Séregé, H. (1902). C.R. Soc. Biol., Paris, 54, 201.

Snyder, L. H. (195I). Genetics in the 20th Century. New York: The Macmillan Co.

Tidy, H. (1952). Brit. med. $\mathcal{F}$. ii, 1 .

Waters, N. F., Groschke, A. C. \& Scott, H. M. (I950). Poult. Sci. 29, 685.

Widdowson, E. M. (1947). Spec. Rep. Ser. med. Res. Coun., Lond., no. 257. 